\title{
STUDI FOTOGRAMETRI JARAK DEKAT DALAM PEMODELAN 3D DAN ANALISIS VOLUME OBJEK
}

\author{
Defry Mulia, Hepy Hapsari \\ Program Studi Teknik Geomatika FTSP-ITS, Kampus ITS Sukolilo, Surabaya, 60111 \\ Email : defry_jp@yahoo.com, hepihapsari@gmail.com
}

\begin{abstract}
Abstrak
Fotogrametri adalah sebuah proses untuk memperoleh informasi metris mengenai sebuah objek melalui pengukuran yang dibuat pada hasil foto baik dari udara maupun dari permukaan tanah. Interpretasi foto didefinisikan sebagai ekstraksi dari informasi kualitatif mengenai foto udara dari sebuah objek oleh analisis visual manusia dan evaluasi fotografi (Edward dan James 2004). Dalam disiplin ilmu fotogrametri dipelajari berbagai metode untuk mengklasifikasikan dan menginterpretasi foto udara dengan berbagai metode.
\end{abstract}

Pengolahan data dilakukan dengan pengambilan gambar objek menggunakan kamera non metric, pengukuran menggunakan Electronic Total Station (ETS) dan roll meter yang kemudian dilakukan kalibrasi kamera menggunakan Sotware Photomodeler Scanner untuk mendapatkan parameter internal kamera. Kemudian melakukukan penandaan titik pada foto sampai akhirnya pembentukan objek 3 dimensi dan volume objek. Selanjutnya melakukan perbandingan dengan hasil pengolahan data thacymetri.

Hasil penetilian ini menunjukkan bahwa data foto pada fotogrametri jarak dekat belum bisa dijadikan acuan dalam proses pembentukan 3 dimensi maupun perhitungan volumenya. Perkiraan volume pada objek lemari menggunakan metode fotogrametri jarak dekat adalah $0,903 \mathrm{~m}^{3}$ dan dengan menggunakan rol meter adalah $0,192 \mathrm{~m}^{3}$. Sementata itu, volume objek gundukan berumput menggunakan metode thacymetri adalah $162,164987 \mathrm{~m}^{3}$ dan luas adalah $30 \mathrm{~m}^{2}$.

Kata Kunci : Fotogrametri, Non-Metrik, IOP

\section{PENDAHULUAN \\ Latar Belakang}

Volume penggalian dan penimbunan suatu material merupakan hal yang penting dalam banyak pekerjaan teknik dan pertambangan. Akurasi bentuk dan estimasi volume dari material tersebut adalah penting dalam banyak aplikasi, misalnya studi erosi, estimasi pengambilan bahan tambang, dan penilaian lahan untuk konstruksi (Schulz dan Schachter 1980 dalam Yakara dan Yilmazb 2008). Umumnya perhitungan volume menggunakan metode trapesium (segiempat atau segitiga prisma), perpotongan melintang (trapezoidal, Simpson, and average formula), dan metode lainnya (Simpson-based, Cubic spline, and Cubic Hermite formula) telah ada dalam literatur (Yanalak 2005 dalam Yakara danYilmazb 2008).

Metode yang digunakan untuk melakukan pengukuran volume suatu material adalah menggunakan metode tachymetri untuk mengetahui koordinat suatu titik dengan menggunakan alat ukur Electronic Total Station (ETS). Untuk mendapatkan bentuk permukaan tanah terbaik sangat bergantung pada bentuk permukaan, distribusi titik dan metode interpolasi. Tetapi dengan bertambahnya titik akan berarti menambah waktu dan biaya. Kadang-kadang untuk mendapatkan titik geodetik dapat beresiko dan mustahil. Karena itu, bentuk permukaan tanah tidak dapat diwakili dengan baik.

Dengan adanya perkembangan teknologi fotogrametri, diharapkan dapat membuat kemudahan untuk melakukan pemodelan tiga dimensi dari suatu objek. Dengan adanya teknologi otomatisasi image matching, mempermudah dalam pengambilan titik sampel yang akan digunakan untuk pembuatan Digital Surface Model (DSM).

Pada penelitian ini akan mengkaji perbandingan hitungan volume dengan menggunakan Fotogrametri Jarak Dekat (CRP) dan Thacymetri. Metode CRP menggunakan kamera DSLR nonmetrik Canon EOS 5D. Objek yang dibutuhkan dalam penelitian CRP adalah grid sebagai data untuk kalibrasi kamera, lemari dan gundukan 
berumput sebagai bahan untuk perhitungan volume. Pengolahan data menggunakan Software Photomodeler Scanner yang bersifat open source.

\section{Perumusan Masalah}

Rumusan masalah dalam penelitian ini adalah :

1. Bagaimana hasil kalibrasi kamera kamera pada Software Photomodeler Scanner?

2. Bagaimana hasil EOP dari proses orientasi relatif dan DSM menggunakan Software Photomodeler Scanner?

3. Bagaimana hubungan antara potensi panas bumi yang ada dengan langkah strategis MP3EI

\section{Batasan Masalah}

Batasan masalahan dari penelitian ini adalah:

1. Objek yang dijadikan bahan pengukuran dari tugas akhir ini yaitu objek lemari dan objek kurang beraturan gundukan berumput.

2. Metode penghitungan volume yang digunakan adalah metode bangun ruang balok dan thacymetri.

3. Software pengolahan menggunakan Software Photomodeler Scanner dengan prinsip epipolar geometry dan metode image matching.

\section{Tujuan Penelitian}

1. Mendapatkan parameter orientasi dalam dari kalibrasi kamera.

2. Membuat model 3D dan DSM (Digital Surface Model) dari objek yang diteliti.

3. Mengihitung volume menggunakan DSM.

4. Analisa ketelitian dengan membandingkan perhitungan hasil volume dengan metode close range photogrammetry dan thacymetri.

\section{METODOLOGI PENELITIAN}

\section{Lokasi Penelitian}

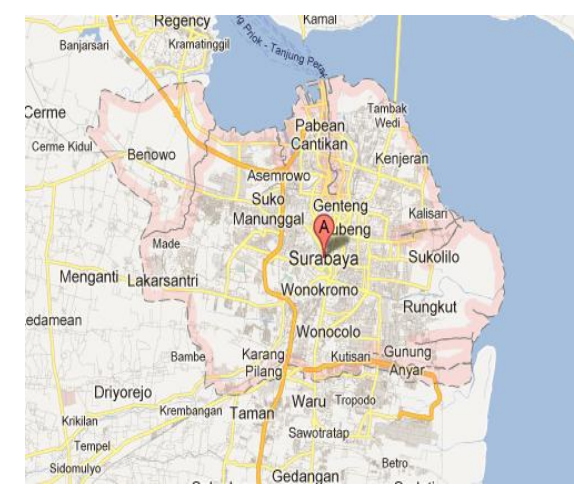

Gambar 1. Lokasi Daerah penelitian

\section{Data Dan Peralatan \\ Data}

Data yang digunakan dalam penelitian ini adalah:

Data foto diambil dengan kamera non metrik atau kamera digital yaitu lemari dan gundukan berumput.

\section{Peralatan}

Peralatan yang digunakan dalam penelitian ini adalah:

1. Perangkat Keras (Hardware)
a. Laptop
b. Kamera Digital Canon EOS 5D Mark II

2. Perangkat Lunak (Software)
a. Sistem Operasi Windows 7
b. Microsoft Office 2010
c. Software pengolahan data digital
d. Software pengolahan fotogrametri

\section{Tahapan Pengolahan Data}

1. Kalibrasi Kamera

Selain dapat menghasilkan IOP, kalibrasi kamera juga bisa menghasilkan Externeal Orientation Parameter (EOP), karena kemungkinan mengingat kamera digital nonmetrik yang memiliki geometri tidak baik.

2. Pengolahan Data Fotogrametri Rentang Dekat

1. Suhu Data Masukan

Data yang diperlukan sebagai masukan adalah nilai parameter kalibrasi kamera yang digunakan dan foto hasil pemotretan objek (lemari dan gundukan berumput). 
2. Pembuatan Titik Sampel

Titik-titik sampel yang akan digunakan untuk pembuatan Digital Surface Model (DSM) dilakukan dengan dua cara yaitu secara manual dan otomatis. Proses otomisasi image matching pada objek gundukan berumput dilakukan penandaan titik sampel secara manual dan otomatis, pada objek lemari dilakukan secara manual. Penandaan titik sampel secara manual dengan menandakan titik di tepi objek.

3. Foto Terkoreksi

Data foto bisa dikatakan terkoreksi apabila RMS yang dihasilkan dari proses image matching kecil dari 0 (nol). Jika RMS rata-rata dari pengolah 2 foto atau lebih masih melebihi 0 (nol), maka dilakukan pembuatan titik sampel kembali.

4. Orientasi Relatif

Pada proses ini mencari pasangan titik dari beberapa foto yang diamati untuk mengetahui parameter orientasi luar kamera (EOP).

5. Intersection

Merupakan teknik menentukan koordinat titik-titik objek pada dua gambar atau lebih yang saling bertampalan sehingga diketahui posisi secara 3D. Dimana proses ini membutuhkan enam parameter orientasi luar (EOP) untuk dua foto yang bertampalan.

6. Pembentukan Model 3D dan DSM.

3. Pengambilan dan Pengolahan Data Metode Tachymetri

1. Pengukuran Titik Kontrol dan Titik Detail. Kerangka dasar untuk pengukuran menggunakan kerangka dasar yang telah tersedia di sekitar daerah yang akan dipetakan. Alat yang digunakan dalam pengukuran titik control objek dan titik detail adalah ETS Topcon. Pengamatan yang diambil yaitu data sudut horizontal, sudut zenith, dan jarak miring.

2. Pengolahan Data Tachymetri sehingga diperoleh beda tinggi dari objek yang diukur. Dari beda tinggi itu dapat digambarkan Digital Surface Model (DSM) sehingga diperoleh volume objek.

4. Hitungan Volume

Proses perhitungan volume adalah tahap akhir dari penelitian tugas akhir ini. Hasil perhitungan volume menggunakan DSm dan ETS akan dibandingkan pada akhirnya.
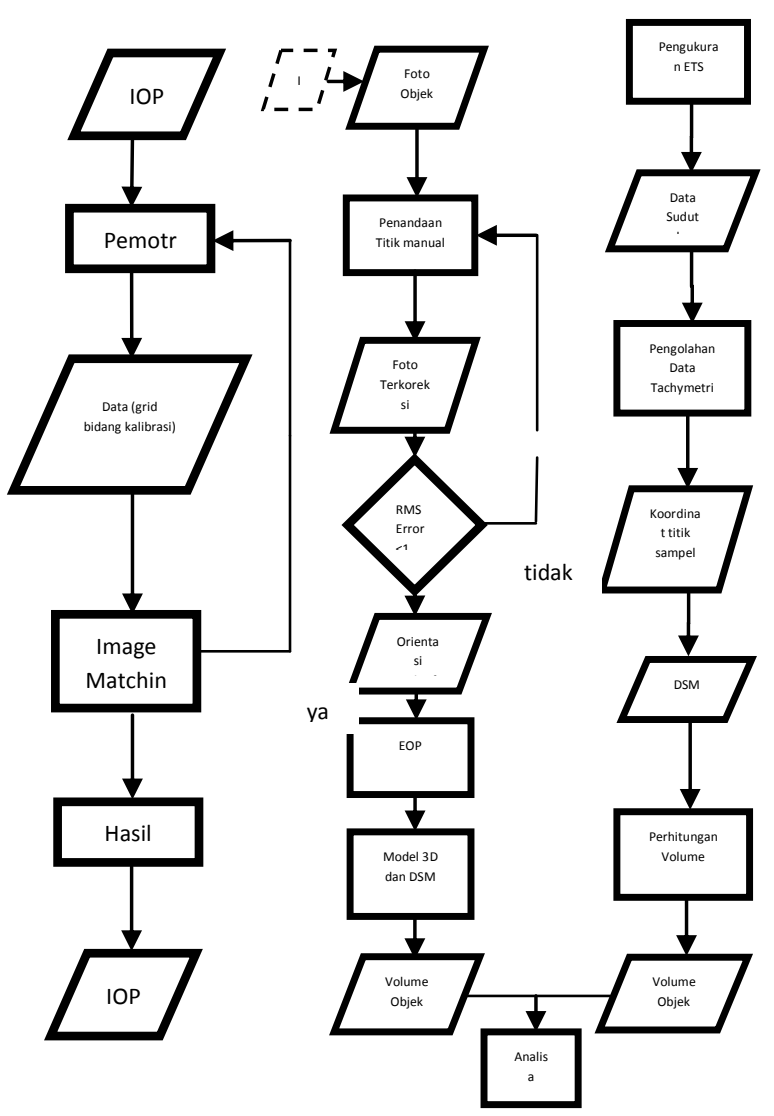

$f, \mathrm{X}_{0}, \mathrm{Y}_{0}, \mathrm{~K} 1$,

$\mathrm{K} 2, \mathrm{~K} 3, \mathrm{P} 1, \mathrm{P} 2$

\section{Gambar 2. Diagram Tahap Pengolahan Data}

HASIL DAN PEMBAHASAN

\section{Kalibrasi Kamera}

Metode kalibrasi pada perangkat lunak ini pada prinsipnya menghitung IOP untuk mendapatkan unsur-unsur orientasi dalam antara lain panjang focus terkalibrasi $(f)$, posisi titik utama foto (X${ }_{0}, \mathrm{Y}_{0}$ ) dan koefisien distorsi lensa (K1, K2, K3, P1, P2) kamera secara analitis dengan menggunakan self calibration bundle adjustment terhadap titik target.

Pengambilan data kalibrasi dilakukan di dalam ruangan dengan menggunakan bidang 2 dimensi berupa kertas putih berukuran A4 
dengan target titik-titik hitam. Bidang kalibrasi ini merupakan bidang kalibrasi default dari perangkat lunak Photomodeler.

Tabel 1. Hasil perhitungan IOP menggunakan self calibration

\begin{tabular}{|c|c|c|}
\hline \multicolumn{3}{|c|}{ Presisi atau stadar deviasi } \\
\hline \multicolumn{3}{|c|}{ Camera Canon EOS 5D Mark II } \\
\hline Parameter Orientasi & & Deviasi \\
\hline Dalam & Nilai (mm) & $(\mathrm{mm})$ \\
\hline Focal Length & 24.791 & 0.004 \\
\hline $\mathrm{Xp}$ & 18.021 & 0.005 \\
\hline$Y p$ & 12.197 & 0.006 \\
\hline Fw & 36.528 & 0.002 \\
\hline Fh & 24.333 & - \\
\hline & & $1.90 \mathrm{E}-$ \\
\hline K1 & $1.54 \mathrm{E}-04$ & 06 \\
\hline K2 & 0 & 0 \\
\hline K3 & 0 & 0 \\
\hline & & $2.50 \mathrm{E}-$ \\
\hline P1 & $1.72 \mathrm{E}-05$ & 06 \\
\hline & & $2.70 \mathrm{E}-$ \\
\hline $\mathrm{P} 2$ & $2.28 \mathrm{E}-05$ & 06 \\
\hline
\end{tabular}

Tabel 2. Kualitas Hasil Kalibrasi Kamera Quality

\begin{tabular}{ccc}
\hline & Total Number & 12 \\
\cline { 2 - 3 } Photographs & Number & \\
& Oriented & 12 \\
\hline & Canon EOS 5D Mark II \\
\cline { 2 - 3 } & Calibration & yes \\
\cline { 2 - 3 } Camera & $\begin{array}{c}\text { Number of } \\
\text { photos using } \\
\text { camera }\end{array}$ \\
\hline
\end{tabular}

Average Photo

Point Coverage

$14 \%$

\begin{tabular}{|c|c|c|}
\hline & Overal RMS & 0.114 pixels \\
\hline & Max & 0.448 pixels \\
\hline & Min & 0.071 pixels \\
\hline $\begin{array}{c}\text { Point } \\
\text { Marking }\end{array}$ & Max & 0.229 pixels \\
\hline Residual & Min & 0.034 pixels \\
\hline Point & $\operatorname{Max}$ & $0.00069 \mathrm{~m}$ \\
\hline Tighness & Min & $0.00013 \mathrm{~m}$ \\
\hline & Overal RMS & \\
\hline & Vector Length & $8.36 \mathrm{e}-005 \mathrm{~m}$ \\
\hline & Max Vector & \\
\hline & Length & $9.02 \mathrm{e}-005 \mathrm{~m}$ \\
\hline Point & Min Vector & \\
\hline Precision & Length & $8.24 \mathrm{e}-005 \mathrm{~m}$ \\
\hline
\end{tabular}

\section{Orientasi Relatif}

Orientasi relatif merupakan proses untuk menentukan nilai perputaran sudut rotasi dan pergeseran posisi antara dua foto. Proses ini dilakukan dengan cara memberikan nilai posisi dan orientasi untuk foto pertama, kemudian dilakukan proses perhitungan nilai posisi dan orientasi pada foto kedua menggunakan parameter dari posisi pertama dan koordinat foto dari kedua buah foto. Dalam proses orientasi menghasilakan sebuah nilai relatif antara dua buah foto tersebut. Yaitu menetapkan enam unsur orientasi luar (EOP), yaitu posisi kamera $\left(X_{L}, Y_{L}, Z_{L}\right)$, rotasi sudut $(\omega$, $\phi, \mathrm{k})$.

1. Objek lemari

Secara garis besar pertampalan atau overlay antar foto tidak boleh kurang dari $60 \%$. Dalam proses ini dilakukan penentukan titik dimana posisi dan nama titik pada foto 1 harus sama dengan yang ditampilkan pada foto 2, begitu juga seterusnya. Dari penggabungan beberapa foto harus mempunyai 1 foto sebagai referensi. 
Berikut adalah beberapa tampilan data hasil pengolahan overlay foto objek lemari dari berbagai sudut:

Tabel 3a. Orientasi relatif dua foto sisi depan lemari

\begin{tabular}{|c|c|c|c|c|}
\hline Photos & $x$ & Y & z & $\begin{array}{c}\text { Tightnes } \\
\mathrm{s} \\
\text { (percent) }\end{array}$ \\
\hline 1,2 & 0.038 & 0.377 & -0.930 & 0.041 \\
\hline 1,2 & -0.598 & 0.377 & -0.854 & 0.059 \\
\hline 1,2 & 0.009 & -0.393 & -0.851 & 0.108 \\
\hline 1,2 & -0.513 & -0.393 & -0.791 & 0.052 \\
\hline 1,2 & 0.001 & -0.032 & -0.877 & 0.003 \\
\hline 1,2 & 0.001 & -0.024 & -0.877 & 0.007 \\
\hline 1,2 & -0.537 & -0.022 & -0.823 & 0.065 \\
\hline 1,2 & -0.536 & -0.031 & -0.821 & 0.062 \\
\hline 1,2 & -0.003 & -0.204 & -0.868 & 0.087 \\
\hline 1,2 & -0.003 & -0.196 & -0.866 & 0.082 \\
\hline
\end{tabular}

Tabel 3b. Orientasi relatif dua foto sisi depan lemari

\begin{tabular}{ccccc}
\hline Photos & Angle & $\begin{array}{c}\text { RMS } \\
\text { Residual } \\
\text { (pixels) }\end{array}$ & $\begin{array}{c}\text { Largest } \\
\text { Residual } \\
\text { (pixels) }\end{array}$ & $\begin{array}{c}\text { Photo } \\
\text { Largest } \\
\text { Residual }\end{array}$ \\
\hline 1,2 & $\begin{array}{c}12.504 \\
\text { degs }\end{array}$ & 0.967 & 1.009 & 2 \\
\hline 1,2 & $\begin{array}{c}11.744 \\
\text { degs }\end{array}$ & 1.397 & 1.438 & 1 \\
\hline 1,2 & $\begin{array}{c}13.850 \\
\text { degs }\end{array}$ & 2.903 & 3.006 & 2 \\
\hline 1,2 & $\begin{array}{c}13.440 \\
\text { degs }\end{array}$ & 1.407 & 1.451 & 1 \\
\hline 1,2 & $\begin{array}{c}14.503 \\
\text { degs }\end{array}$ & 0.079 & 0.082 & 2 \\
\hline 1,2 & $\begin{array}{c}14.501 \\
\text { degs }\end{array}$ & 0.188 & 0.195 & 2 \\
\hline
\end{tabular}

\begin{tabular}{ccccc}
\hline 1,2 & $\begin{array}{c}13.619 \\
\operatorname{degs}\end{array}$ & 1.591 & 1.628 & 1 \\
\hline 1,2 & $\begin{array}{c}13.657 \\
\text { degs }\end{array}$ & 1.526 & 1.562 & 1 \\
\hline 1,2 & $\begin{array}{c}14.436 \\
\text { degs }\end{array}$ & 2.214 & 2.288 & 2 \\
\hline 1,2 & $\begin{array}{c}14.501 \\
\text { degs }\end{array}$ & 2.085 & 2.154 & 2 \\
\hline
\end{tabular}

Tabel 4. Enam unsur orientasi luar (EOP) objek lemari

\begin{tabular}{|c|c|c|c|c|c|c|}
\hline \multirow{2}{*}{$\begin{array}{c}\text { Fot } \\
0\end{array}$} & \multicolumn{6}{|c|}{ Parameter } \\
\hline & $\mathrm{Xc}$ & Yc & Zc & Omega & Phi & $\begin{array}{c}\text { Kapp } \\
\text { a }\end{array}$ \\
\hline 1 & $\begin{array}{c}0.55 \\
1\end{array}$ & $\begin{array}{c}0.06 \\
1\end{array}$ & $\begin{array}{c}- \\
0.36 \\
1\end{array}$ & $\begin{array}{c}-9.089 \\
\text { deg }\end{array}$ & $\begin{array}{c}37.017 \\
\text { deg }\end{array}$ & $\begin{array}{r}5.475 \\
\text { deg }\end{array}$ \\
\hline 2 & $\begin{array}{c}- \\
0.47 \\
7\end{array}$ & $\begin{array}{c}0.04 \\
2\end{array}$ & $\begin{array}{c}- \\
0.26 \\
1\end{array}$ & $\begin{array}{c}-5.801 \\
\text { deg }\end{array}$ & $\begin{array}{c}-32.017 \\
\text { deg }\end{array}$ & $\begin{array}{c}- \\
1.883 \\
\text { deg }\end{array}$ \\
\hline 3 & $\begin{array}{c}- \\
0.39 \\
6\end{array}$ & $\begin{array}{c}0.03 \\
2\end{array}$ & $\begin{array}{c}- \\
0.21 \\
5\end{array}$ & $\begin{array}{c}-3.846 \\
\text { deg }\end{array}$ & $\begin{array}{c}-41.739 \\
\text { deg }\end{array}$ & $\begin{array}{c}- \\
0.959 \\
\text { deg }\end{array}$ \\
\hline 4 & $\begin{array}{c}- \\
0.55 \\
4\end{array}$ & $\begin{array}{c}0.03 \\
4\end{array}$ & $\begin{array}{c}- \\
0.32 \\
5\end{array}$ & $\begin{array}{c}-4.856 \\
\text { deg }\end{array}$ & $\begin{array}{c}-22.504 \\
\text { deg }\end{array}$ & $\begin{array}{c}- \\
1.873 \\
\text { deg }\end{array}$ \\
\hline 5 & $\begin{array}{c}0.64 \\
7\end{array}$ & $\begin{array}{c}0.04 \\
1\end{array}$ & $\begin{array}{c}- \\
0.37 \\
1\end{array}$ & $\begin{array}{c}-4.669 \\
\text { deg }\end{array}$ & $\begin{array}{c}27.143 \\
\text { deg }\end{array}$ & $\begin{array}{r}3.704 \\
\text { deg }\end{array}$ \\
\hline 6 & $\begin{array}{c}0.49 \\
9\end{array}$ & $\begin{array}{c}0.04 \\
8\end{array}$ & $\begin{array}{c}- \\
0.28 \\
5\end{array}$ & $\begin{array}{c}-7.907 \\
\text { deg }\end{array}$ & $\begin{array}{c}44.543 \\
\text { deg }\end{array}$ & $\begin{array}{c}4.608 \\
\text { deg }\end{array}$ \\
\hline 7 & $\begin{array}{c}0.04 \\
3\end{array}$ & $\begin{array}{c}0.00 \\
4\end{array}$ & $\begin{array}{c}0.01 \\
1\end{array}$ & $\begin{array}{c}-0.136 \\
\text { deg }\end{array}$ & $\begin{array}{c}2.741 \\
\operatorname{deg}\end{array}$ & $\begin{array}{c}- \\
0.254 \\
\text { deg }\end{array}$ \\
\hline
\end{tabular}


Tabel 5. Enam unsur orientasi luar (EOP) objek

\begin{tabular}{|c|c|c|c|c|c|c|c|}
\hline \multirow{2}{*}{ Fot } & & \multicolumn{6}{|c|}{ Parameter } \\
\hline & & Xc & Yc & Zc & Omega & Phi & Kappa \\
\hline \multirow{2}{*}{$\begin{array}{c}1 \\
\text { dan } \\
2\end{array}$} & 1 & $\begin{array}{c}- \\
0.00003\end{array}$ & -0.0006 & -0.003 & $\begin{array}{c}0.021 \\
\text { deg }\end{array}$ & $\begin{array}{c}-0.025 \\
\text { deg }\end{array}$ & $\begin{array}{c}-0.001 \\
\text { deg }\end{array}$ \\
\hline & 2 & 0.335 & -0.011 & -0.021 & $\begin{array}{c}0.134 \\
\text { deg }\end{array}$ & $\begin{array}{c}0.988 \\
\operatorname{deg}\end{array}$ & $\begin{array}{c}-0.705 \\
\text { deg }\end{array}$ \\
\hline \multirow{2}{*}{$\begin{array}{c}3 \\
\text { dan } \\
4\end{array}$} & 3 & 0.003 & $\begin{array}{c}- \\
0.00002\end{array}$ & 0.0007 & $\begin{array}{c}0.003 \\
\text { deg }\end{array}$ & $\begin{array}{c}0.095 \\
\operatorname{deg}\end{array}$ & $\begin{array}{c}-0.023 \\
\text { deg }\end{array}$ \\
\hline & 4 & 0.861 & -0.002 & 0.360 & $\begin{array}{c}1.072 \\
\text { deg }\end{array}$ & $\begin{array}{c}3.167 \\
\operatorname{deg}\end{array}$ & $\begin{array}{c}-0.982 \\
\text { deg }\end{array}$ \\
\hline \multirow{2}{*}{$\begin{array}{c}5 \\
\text { dan } \\
6\end{array}$} & 5 & -0.031 & 0.017 & 0.011 & $\begin{array}{c}-0.718 \\
\text { deg }\end{array}$ & $\begin{array}{c}-1.094 \\
\operatorname{deg}\end{array}$ & $\begin{array}{c}0.082 \\
\text { deg }\end{array}$ \\
\hline & 6 & 0.374 & 0.068 & -0.103 & $\begin{array}{c}-8.383 \\
\text { deg }\end{array}$ & $\begin{array}{c}1.185 \\
\operatorname{deg}\end{array}$ & $\begin{array}{c}0.584 \\
\text { deg }\end{array}$ \\
\hline \multirow{2}{*}{$\begin{array}{c}6 \\
\text { dan } \\
7\end{array}$} & 6 & 0.033 & -0.011 & -0.015 & $\begin{array}{c}0.428 \\
\text { deg }\end{array}$ & $\begin{array}{c}1.189 \\
\operatorname{deg}\end{array}$ & $\begin{array}{c}-0.006 \\
\text { deg }\end{array}$ \\
\hline & 7 & 0.392 & -0.013 & -0.432 & $\begin{array}{c}5.154 \\
\text { deg }\end{array}$ & $\begin{array}{c}11.730 \\
\operatorname{deg}\end{array}$ & $\begin{array}{c}1.053 \\
\text { deg }\end{array}$ \\
\hline
\end{tabular}

\section{gundukan berumput}

\section{Pemodelan 3D Objek dan DSM}

Setelah melakukan overlay atau pertampalan dari beberapa foto, baik itu objek lemari maupun gundukan berumput, diperoleh pemodelan objek secara 3 dimensi.

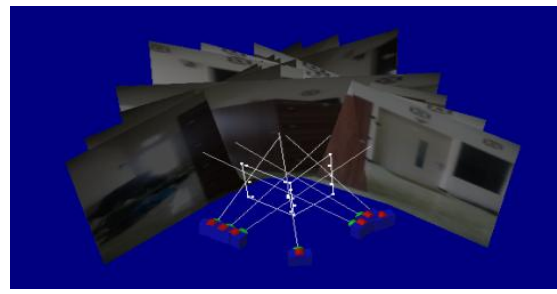

Gambar 3. Pemodelan 3D objek lemari dari 2 sisi

Sedangkan untuk objek gundukan berumput, tidak hanya dilakukan penandaan titik secara manual, melainkan juga dilakukan penandaan titik secara otomatis.

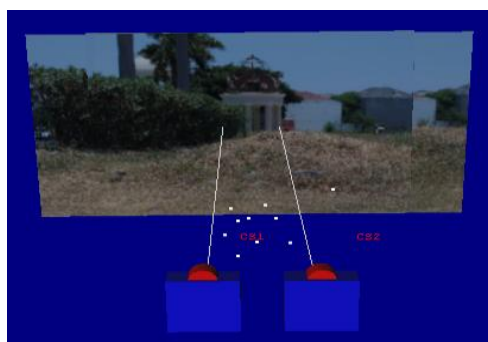

Gambar 4. Penandaan titik secara manual dan otomatis pada objek gundukan berumput

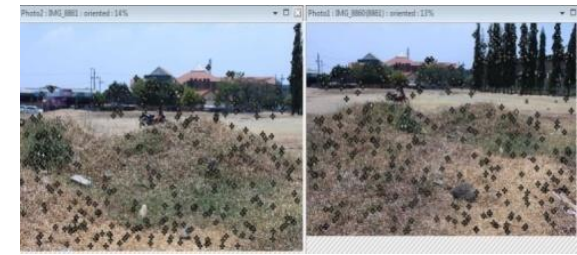

Gambar 5. Pemodelan 3D objek gundukan berumput

\section{Volume Objek Lemari}

Metode hitungan objek lemari adalah menggunakan rumus balok.

Tabel 6. Hasil Hitungan Volume Lemari

\begin{tabular}{ccccc}
\hline $\begin{array}{c}\text { Metode } \\
\text { Pengukuran }\end{array}$ & $\begin{array}{c}\text { Panjang } \\
(\mathrm{m})\end{array}$ & $\begin{array}{c}\text { Lebar } \\
(\mathrm{m})\end{array}$ & $\begin{array}{c}\text { Tinggi } \\
(\mathrm{m})\end{array}$ & $\begin{array}{c}\text { Volume } \\
\left(\mathrm{m}^{3}\right)\end{array}$ \\
\hline CRP & 0.457 & 0.423 & 0.556 & 0.107 \\
\hline Roll Meter & 0.400 & 0.400 & 1.200 & 0.192 \\
\hline
\end{tabular}

Dari hasil perhitungan volume menggunakan metode Close Range Photogrammetry (CRP), diperoleh volume sebesar $0.107 \mathrm{~m}^{3}$, sedangkan hasil perhitungan volume objek lemari metode roll meter adalah $0.192 \mathrm{~m}^{3}$. Dengan demikian hasil perbandingan antara metode CRP dengan perhitungan objek secara langsung menggunakan roll meter tidak terlalu jauh, yaitu sebesar $0.085 \mathrm{~m}^{3}$.

\section{Pengolahan Data Thacymetri Objek} Gundukan Berumput

Kerangka dasar untuk pengukuran menggunakan kerangka dasar yang telah tersedia di sekitar daerah yang akan dipetakan. Alat yang digunakan dalam pengukuran titik control objek dan titik detail adalah Electronic Total Stasion 
Topcon. Pengamatan yang diambil yaitu data sudut horizontal, sudut zenith, dan jarak miring.

Untuk dapat memodelkan kontur dan bentuk 3D dari data yang telah diperoleh, minimum harus memiliki 2 permukaan. Dimisalkan permukaan 1 adalah data hasil pengukuran di lapangan dan permukaan 2 adalah data perencaan yang memiliki eleveasi maksimum dan elevasi minimum sama tinggi yaitu 0 meter.

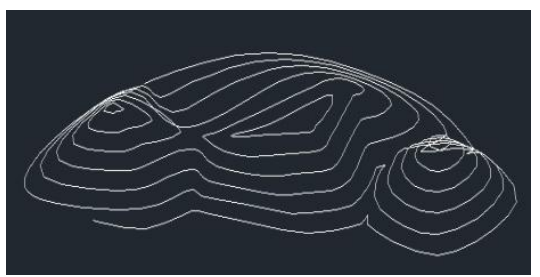

Gambar 6. DSM Gundukan Berumput

\section{Hitungan Volume Objek Gundukan Berumput}

Untuk objek jenis tidak beraturan yaitu gundukan berumput, penentuan volume menggunakan metode thacymetri. Dalam kasus ini, harus terdapat 2 permukaan (surface).

Tabel 7. Hasil Hitungan Volume Gundukan Berumput Menggunakan ETS

\begin{tabular}{lr}
\hline volume cut $\left(\mathrm{m}^{3}\right)$ & 162.165 \\
\hline volume fill $\left(\mathrm{m}^{3}\right)$ & 0 \\
\hline volume hasil $\left(\mathrm{m}^{3}\right)$ & 162.165 \\
\hline jumlah titik & 653 \\
\hline elevasi minimum $(\mathrm{m})$ & 5.3 \\
& \\
\hline elevasi maksimum $(\mathrm{m})$ & 5.9 \\
\hline & $1028.099 ;$ \\
koordinat minimum $(\mathrm{x}, \mathrm{y})$ & 985.112 \\
\hline koordinat maksimum $(\mathrm{x}, \mathrm{y})$ & \\
\hline
\end{tabular}

\section{PENUTUP}

Kesimpulan

Dari penelitian ini dapat diambil beberapa kesimpulan, yaitu :

1. Parameter Orientasi Dalam kamera pada hasil kalibrasi kamera yaitu focal length = 24.790, posisi titik utama foto $\left(X_{P} ; Y_{P}\right)=$ 18.021;12.197, dan koefisien distorsi lensa $\mathrm{K} 1=0.00015, \mathrm{~K} 2=0, \mathrm{~K} 3=0, \mathrm{P} 1=0.000017$, dan P2 $=0.000022$

2. Pemodelan objek beraturan yang diwakili oleh lemari berhasil dilakukan, sementara itu objek yang tidak beraturan seperti gundukan berumput tidak berhasil dilakukan.

3. Volume objek lemari berdasarkan roll meter adalah $0.192 \mathrm{~m}^{3}$ dan berdasarkan CRP adalah $0.107 \mathrm{~m}^{3}$. Untuk objek gundukan berumput, berdasarkan hasil thacymetri $162.165 \mathrm{~m}^{3}$ dan berdasarkan CRP belum berhasil ditentukan. Perhitungan volume suatu objek dengan metode fotogrametri rentang dekat (CRP) merupakan alternatif yang kurang akurat untuk objek yang tidak beraturan.

4. Hasil Uji statistik pengukuran objek lemari dengan membandingkan metode Roll Meter dengan CRP memperoleh nilai $\mathrm{P}=$ 0.394, sehingga disimpulkan metode CRP untuk objek yang beraturan masih bisa dikatakan valid.

\section{Saran}

1. Untuk jenis objek yang tidak beraturan yaitu gundukan berumput, demi mendapatkan hasil orientasi relatif yang bagus seharusnya dipasang tanda atau titik kontrol di objek gundukan.

2. Pada objek lemari, karena perbandingan hitungan volume antara metode CRP dan menggunakan roll meter tidak terjadi perbedaan yang signifikan maka sebaiknya digunakan bentuk lemari yang lebih bervariasi atau yang berbeda ukuran untuk menguji ketelitian perangkat lunak photomodeler scanner.

3. Untuk penelitian selanjutnya, perangkat lunak photomodeler scanner tidak baik dalam proses pengolahan objek tidak beraturan tanpa titik kontrol. 


\section{DAFTAR PUSTAKA}

Atkinson. 1996. Close Range Photogrametry and Machine Vision. WhittlesPublishing. Scotland, UK.

Cahyono, A.B. dan Hapsari, H.H. 2008. Petunjuk Praktikum Fotogrametri 1. Laboratorium Fotogrametri. Program Studi Teknik Geomatika, FTSP, ITS.

Hanifa, R. 2007. Studi Penggunaan Kamera Digital Low-Cost Non-Metrik AutoFocus untuk Pemantauan Deformasi. Tesis. Program Studi Teknik Geodesidan Geomatika. Institut Teknologi Bandung.

Institut Teknologi Telkom. 2008. Fotogrametri. Bandung. Gedung Learning Centre Kampus Institut Teknologi Telkom.

Kusumadarma, A. 2008. Aplikasi Close Range Photogrametry dalam PemetaaanBangun Rekayasa dengan Kamera Dijital Non Metrik Terkalibrasi. TugasAkhir. Program Studi Teknik Geodesi dan Geomatika. Institut Teknologi Bandung.

Ma'ruf, M. 2003. Perbandingan Digital Terrain Model (DTM) Jenis Grid DenganTriangulated Irregular Network (TIN). Tugas Akhir. Program Studi TeknikGeodesi dan Geomatika. Institut Teknologi Bandung.

Saleh, S. 1996. Statistik Induktif. UPP AMP YKPN. Yogyakarta.

Setyadji, B. 2005. Hitung Perataan1. Program Studi Teknik Geodesi danGeomatika. Institut Teknologi Bandung.

Yakara, M. and Yilmazb, H.M. 2008. Using In Volume Computing Of DigitalClose Range Photogrammetry. The International Archives of thePhotogrammetry, Remote Sensing and Spatial Information Sciences. Vol.XXXVII. Part $B 3 b$. Beijing.

Wolf, P.R. 1974. Elemen Fotogrametri Dengan Interpretasi Foto Udara dan Penginderaan Jauh. Madison : McGraw-Hill. 